\title{
Inhibition of Neutrophil Priming and Tyrosyl Phosphorylation by Cepharanthine, a Nonsteroidal Antiinflammatory Drug
}

\author{
Hirotsugu Kobuchia,3, Ming J. Li ${ }^{b, 4}$, Tsuyoshi Matsunoc, Tatsuji Yasuda ${ }^{a, 1}$ and Kozo Utsumi ${ }^{\mathrm{b}}$ \\ ${ }^{a}$ Department of Cell Chemistry, Institute of Cellular and Molecular Biology, Okayama University Medical \\ School, Okayama 700, 'Department of Medical Biology, Kochi Medical School, Nankoku-shi, Kochi 783, and \\ 'Department of Surgery, Okayama University Medical School, Okayama 700, Japan
}

Key words: neutrophil priming/superoxide radical/cepharanthine/tyrosyl phosphorylation

\begin{abstract}
$A B S T R A C T$. Receptor-mediated superoxide $\left(\mathrm{O}_{\overline{2}}\right)$-generation and tyrosyl phosphorylation of neutrophil proteins, such as 58, 65, 84, 108 and $115 \mathrm{kDa}$, were enhanced by priming cells with granulocyte colony stimulating factor (G-CSF) [Akimura, K. et al. Arch. Biochem. Biophys. 298: 703-709, 1992]. To elucidate the possible involvement of tyrosyl phosphorylation of neutrophil proteins in the enhancing mechanism of $O_{2}$ generation, the effect of cepharanthine, a biscoclaurine alkaloid that inhibits phorbol 12-myristate 13-acetate (PMA)- and receptor-mediated $\mathrm{O}_{2}$ generation, on the priming of human peripheral neutrophils (HPPMN) was studied. Both enhancement of formyl-methyonyl-leucyl-phenylalanine (FMLP)-mediated $O_{2}^{\prime}$ generation and tyrosyl phosphorylation of some neutrophil proteins, i.e., 115, 108 and 84 kDa proteins, by HHPMN after treatment with G-CSF were strongly inhibited by cepharanthine in a concentration- and treatment-time-dependent manner. In contrast, inhibition of PMA-mediated $O=$ generation by cepharanthine was weak and independent of treatment time. These results suggest that cepharanthine might inhibit the priming step of neutrophil activation concomitantly with its inhibition of the tyrosyl phosphorylation of some neutrophil proteins that might underlie the mechanism for priming of neutrophils with G-CSF.
\end{abstract}

The phagocytic leukocyte possesses a mechanism for killing microbes (1). However, the circulating neutrophils of healthy humans (HHPMN) are dormant, i.e., in a nonprimed state, and show stimulation-coupled responses only weakly. Upon priming with various ligands, e.g., granulocyte macrophage colony stimulation factor (GM-CSF) $(2,3), \mathrm{G}-\mathrm{CSF}(4), \mathrm{TNF}-\alpha(4,5)$, bacterial cell membrane lipopolysaccharide (LPS) (6), platelet activation factor (PAF) (7), and PMA (8), the reactivity of these cells to various stimuli is greatly enhanced.

Superoxide $\left(\mathrm{O}_{2}\right)$ generation by NADPH oxidase is induced by various particles and soluble ligands (9). Since PMA, an analogue of diacylglycerol, activates neutrophils and generates $\mathrm{O}_{2}$, stimulation-dependent $\mathrm{O}_{2}$ production seems to involve the activation of protein kinase C (PKC) (10). However, 1-(5-isoquinolinesulpho- nyl)-2-methylpiperazine ( $\mathrm{H}-7)$, a $\mathrm{PKC}$ inhibitor, does not completely inhibit FMLP-stimulated $\mathrm{O}_{2}$ generation (11). These results suggest that PKC may not fully account for the activation of NADPH oxidase.

We previously reported that receptor-mediated $\mathrm{O}_{2}^{2}$ generation, but not PMA- and diacylglycerol-mediated generation, by HPPMN was enhanced by priming with TNF- $\alpha$ and G-CSF (12-14). The TNF- $\alpha$ enhanced receptor-mediated reaction was strongly inhibited by tyrosine kinase inhibitors, whereas the PMA-mediated reaction was strongly inhibited by PKC inhibitors (12-14). Recent studies reveal that tyrosyl phosphorylation of neutrophil proteins is stimulated by priming agents, such as PAF (15), GM-CSF (16), TNF- $\alpha$ (17), and G-CSF (17). These results suggest the involvement of tyrosine kinase in the signal transducing pathway for neutrophil priming.

1 To whom address correspondence and reprint requests.

${ }^{2}$ Abbreviations used: CBB, Coomassie brilliant blue; Cyt c, ferricytochrome c; DOG, L- $\alpha-1,2$-dioctanoyl glycerol; EGF, epidermal growth factor; EGTA, ethyleneglycol bis (aminoethylether)-N,N,N',N'-tetraacetic acid; FMLP, formyl + methionyl-leucyl-phenylalanine; G-CSF, granulocyte colony stimulating factor; GM-CSF, granulocyte macrophage colony stimulating factor; H-7, 1-(5-isoquinoline-sulfonyl) methylpiperazine dihydrochloride; KRP, Krebs-Ringer-phosphate; HPPMN, human peripheral neutrophils; LPS, lipopoly-saccharide; $\mathrm{O}_{2}$, superoxide anion; LCL, luminol chemiluminescence; PAF, platelet activation factor; PKC, protein kinase C; PMA, phorbol 12-myristate 13-acetate; PMSF, phenylmethylsulfonyl fluoride; SDS-PAGE, sodium dodecyl sulfate-polyacrylamide gel electrophoresis; ST 638, $\alpha$-cyano-3-ethoxy-4-hydroxy-5-phenylthio-methylcinnamamide; TNF- $\alpha$, tumor necrosis factor- $\alpha$

${ }^{3}$ Permanent address: Institute for Medical Science, Center for Adult Diseases, Kurashiki, Kurashiki 710, Japan.

${ }^{4}$ Permanent address: Department of Biology, Jiamusi Medical College, Jiamusi, Heilongjiang, China. 
Cepharanthine has been used as a therapeutic agent in the treatment of chronic inflammation and inhibition of leukopenia (18). Previous studies in this laboratory revealed that various types of biscoclaurine alkaloids, such as cepharanthine, tetrandrine and isotetrandrine, are potent inhibitors of $\mathrm{O}_{\overline{2}}$ generation by neutrophils $(19,20)$. The mechanism by which these alkaloids inhibit $\mathrm{O}$ generation is postulated to depend on their ability to inhibit NADPH oxidase by stabilizing plasma membranes and/or PKC-dependent protein phosphorylation through the inhibition of substrate- membrane interaction $(21,22)$.

To obtain further insight into the mechanism for neutrophil priming and the action of cepharanthine, the effect of this alkaloid on the enhancement of receptormediated $\mathrm{O}$ - generation in neutrophils primed with TNF- $\alpha$ and G-CSF was studied. The results revealed that cepharanthine significantly inhibited the priming and enhancement of tyrosyl phosphorylation induced by G-CSF and TNF- $\alpha$. The mechanism for priming and the action of cepharanthine are also discussed.

\section{MATERIALS AND METHODS}

Chemicals. Ferricytochrome c (Cyt. c), FMLP, PMA, and zymosan were purchased from Sigma Chemical Co. (St. Louis, MO.). Cepharanthine was donated by Kaken Pharmaceutical Co. Ltd. (Tokyo). H-7 was from Seikagaku Corp. (Tokyo), and epidermal growth factor (EGF) from Funakoshi Co. Ltd. (Tokyo). Human G-CSF and TNF- $\alpha$ were donated by Chugai Pharmaceutical Co. (Tokyo) and Hayashibara Bioscience Research Institute (Okayama, Japan), respectively. Peroxidase-labeled anti-mouse IgG antibody was purchased from Organon Teknika (Durhan, NC). Antiphosphotyrosine antibody (PY-20) and [ $\left.\gamma-{ }^{32} \mathrm{P}\right] \mathrm{ATP}$ were obtained from ICN Radiochemicals (Irvine, CA). Recombinant neutrophil annexin I expressed by yeast was purified in this laboratory (23). All other agents were of analytical grade and were obtained from Nacalai Tesque Co. (Kyoto).

Preparation and priming of neutrophils. HPPNM were isolated from fresh blood of healthy volunteers by the method of Ficoll/Hypaque gradients (24). Isolated neutrophils were washed twice with Krebs-Ringer-phosphate buffer solution (KRP) and were resuspended at a concentration of $1 \times 10^{8}$ cells $/ \mathrm{ml}$. Viability of cells was determined by the trypan blue exclusion method. For the priming of HPPMN $\left(2 \times 10^{6}\right.$ cells $/ \mathrm{ml}), 10 \mathrm{U} / \mathrm{ml}$ of TNF- $\alpha$ and $50 \mathrm{ng} / \mathrm{ml}$ of G-CSF were used (13).

Measurement of superoxide generation. $\mathrm{O}_{2}^{2}$ generation was assayed by the Cyt $\mathrm{c}$ reduction method (25) using a dualbeam spectrophotometer (Shimadzu UV-300). Briefly, the reaction mixture contained in a final volume of $2 \mathrm{ml} \mathrm{KRP,} 1$ $\mathrm{mM} \mathrm{CaCl}_{2}, 20 \mu \mathrm{M}$ Cyt c, $10 \mathrm{mM}$ glucose and $1 \times 10^{6}$ cells $/ \mathrm{ml}$. In the presence or absence of $50 \mathrm{ng} / \mathrm{ml}$ G-CSF, reactions were started by adding ligands, and the change in absorbance at
$550-540 \mathrm{~nm}\left(\mathrm{~A}_{550-540}\right)$ was monitored at $37^{\circ} \mathrm{C} . \mathrm{O}_{2}^{\prime}$ generation was calculated from the rate of superoxide dismutase-inhibitable Cyt $c$ reduction using the extinction coefficient of 21.0 $\mathrm{mM}^{-1}$ (26). Percent inhibition by cepharanthine was calculated at 5 min after the addition of FMLP or PMA.

Measurement of luminol chemiluminescence (LCL). LCL change was measured by a calcium analyzer (Jasco CAF 100 , mode for aequorin chemiluminescence equipped with a thermostatically controlled cuvette holder and a magnet stirrer) $(25,27)$. The reaction mixture of $1 \mathrm{ml} \mathrm{KRP}$ contained $1 \times$ $10^{-4} \mathrm{M}$ luminol, $0.2-1 \times 10^{6} \mathrm{cells}$, and other additives. The reaction was started at $37^{\circ} \mathrm{C}$ by adding a test ligand in the presence or absence of $50 \mathrm{ng} / \mathrm{ml}$ of G-CSF, and light emission was recorded for $15 \mathrm{~min}$. LCL was determined by measuring its peak height (counts per minute) or by calculating the area under the LCL light curve (integral LCL). Percent inhibition by cepharanthine was calculated at $5 \mathrm{~min}$ after the addition of FMLP.

Detection of phosphorylated tyrosine in neutrophil proteins. Phosphorylated tyrosine was detected by immunoblotting with monoclonal antibody for phosphotyrosine, as described in previous papers (15-17). HPPMN $\left(2 \times 10^{6} \mathrm{cells} / \mathrm{ml}\right)$ suspended in $1 \mathrm{ml}$ of KRP were incubated with $50 \mathrm{ng} / \mathrm{ml} \mathrm{G}$ $\mathrm{CSF}$ at $37^{\circ} \mathrm{C}$ in the presence or absence of cepharanthine. The reaction was terminated by adding $0.5 \mathrm{ml}$ of ice-cold $45 \%$ trichloroacetic acid (TCA) solution containing $2 \mathrm{mM}$ PMSF and $1 \mathrm{mM}$ sodium orthovanadate. The precipitant was washed twice with ice-cold ether/ethanol $(1: 1)$, dissolved in SDS sample buffer, and subjected to sodium dodecyl sulfate-polyacrylamide gel electrophoresis (SDS-PAGE). After electrophoresis, proteins were transferred to an Immobilon-P filter (Millipore) by the Sartorious semi-dry blotting apparatus. After blocking for $60 \mathrm{~min}$ with $5 \%$ skim-powdered milk dissolved in $30 \mathrm{mM}$ Tris- $\mathrm{HCl}$ buffer saline (pH 7.5) containing $0.1 \%$ Tween 20 (TBS-T) at room temperature, the filter was incubated with phosphotyrosine-specific monoclonal antibody. The monoclonal antiphosphotyrosine antibody was detected with peroxidase-conjugated rabbit anti-mouse IgG (1/15000 diluted in TBS-T containing $0.5 \%$ skim milk). Peroxidasepositive bands were detected using the ECL Western blotting detection system (Amersham). Molecular masses were determined using Daiichi-Kagaku standards.

EGF receptor/kinase-dependent phosphorylation of protein tyrosine residues. A-431 cells were grown in a culture flask $\left(75 \mathrm{~cm}^{3}\right)$ containing Dulbecco's modified Eagle's medium (Flow Laboratories) supplemented with 10\% fetal bovine serum. The particulate fraction of the culture cells was obtained as described by De $e t$ al. (28). Briefly, the reaction mixture contained in a final volume of $60 \mu 1,20 \mathrm{mM}$ Hepes (pH 7.4), $2 \mathrm{mM} \mathrm{MgCl}_{2}, 1 \mathrm{mM} \mathrm{CaCl} 2,10 \mu \mathrm{M}$ sodium orthovanadate, $15 \mu \mathrm{Ci}(0.585 \mathrm{MBq})\left[\gamma^{-32} \mathrm{P}\right] \mathrm{ATP}, 0.5 \mathrm{mM} \mathrm{CaCl}_{2}, 1$ $\mu \mathrm{g} / \mathrm{ml}$ annexin I and an aliquot of the A-431 total particulate fraction was placed on ice and preincubated for $10 \mathrm{~min}$ at $0^{\circ} \mathrm{C}$ in the presence or the absence of EGF $(2 \mu \mathrm{g} / \mathrm{ml})$. The reaction was initiated by adding $\left[\gamma^{32} \mathrm{P}\right] \mathrm{ATP}$. After $10 \mathrm{~min}$ of incuba- 
tion at $0^{\circ} \mathrm{C}$, the reaction was terminated by adding $30 \mu \mathrm{l}$ of the terminating solution containing $10 \%$ of SDS. SDS-PAGE was performed and phosphorylation of annexin 1 was detected by autoradiography, as previously described (23).

\section{RESULTS}

Effect of G-CSF and cepharanthine on receptor-mediated active oxygen generation. Under nonprimed conditions, the rate of FMLP-induced generation of $\mathrm{O}_{2}$ by normal HPPMN is fairly low $(12,13,29,30)$. FMLPstimulated $\mathrm{O}_{2}$ generation was markedly enhanced by priming cells with either TNF- $\alpha$ or G-CSF in a concentration- as well as in a time-of-exposure-dependent manner $(13,14)$. Cepharanthine inhibited the $\mathrm{O} 2$ generation enhanced by G-CSF in a concentration-dependent manner; the concentration of cepharanthine required for the half-maximum inhibition was $10 \mu \mathrm{M}$ (Figs. 1a and b). This inhibitory action was stronger than that for FMLP-induced $\mathrm{O}_{2}$ generation without priming by GCSF (data not shown). Viability of neutrophils was not changed after treatment with $50 \mu \mathrm{M}$ cepharanthine for $30 \mathrm{~min}$. When neutrophils responded to various stimuli, LCL, which reflected various active oxygen species, in- creased markedly (20). G-CSF also enhanced the FMLP-induced LCL (14) by a cepharanthine-inhibitable mechanism (Figs. 2a and b). The concentration of cepharanthine for the half-maximum inhibition was similar to that for the inhibition of $\mathrm{O}$ generation.

Time-dependent inhibition of active oxygen generation by cepharanthine. To gain further insight into the mechanism for inhibition by cepharanthine, the effect of incubation time was investigated with FMLP. As shown in Fig. 3, the inhibition rate of cepharanthine was reduced from $100 \%$ to $25 \%$ by reducing the incubation time with cepharanthine. This time dependence is shown in the inset in Fig. 3. A similar time dependent inhibitory effect of cepharanthine was observed on the LCL response (Fig. 4).

Effect of cepharanthine on PMA-stimulated active oxygen generation by HPPMN. Previous studies revealed that cepharanthine strongly inhibited the active oxygen generation by PMA-stimulated HPPMN (19, 20 ). We also reported that the priming by G-CSF or TNF- $\alpha$ did not affect the rate of $\mathrm{O}_{2}$ generation induced by PMA or DG $(12,13,29,30)$. To elucidate the inhibitory mechanism of cepharanthine, the effect of preincubation time on PMA-stimulated $\mathrm{O}_{2}$ generation by

a

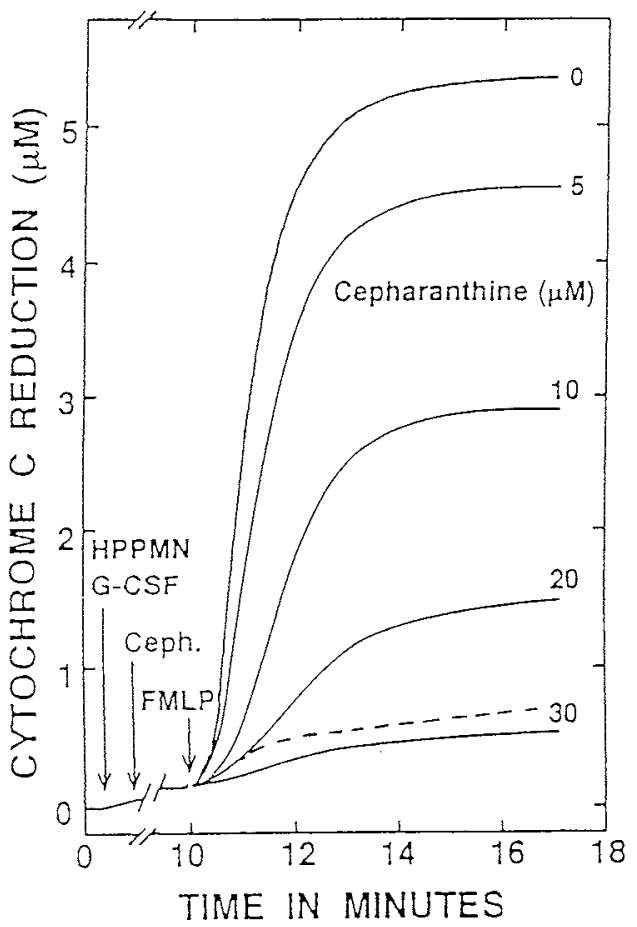

b

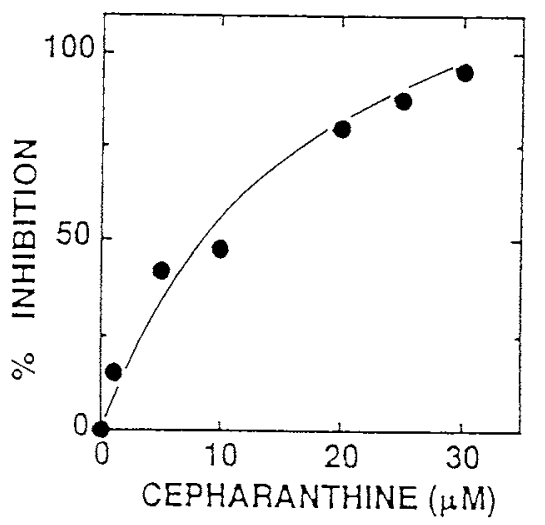

Fig. 1. Effect of cepharanthine on FMLP-induced $\mathrm{O}_{2}^{\prime}$ generation by G-CSF-treated HPPMN. HPPMN $\left(1 \times 10^{6}\right.$ cells $\left./ \mathrm{ml}\right)$ were incubated in $\mathrm{KRP}$ containing $1 \mathrm{mM} \mathrm{CaCl}_{2}, 10 \mathrm{mM}$ glucose, and $20 \mathrm{mM} \mathrm{Cyt}$. c, in the presence or absence of $50 \mathrm{ng} / \mathrm{ml} \mathrm{G}-\mathrm{CSF}$ at $37^{\circ} \mathrm{C}^{\circ} \mathrm{O}_{2}$ generation was triggered by adding $1.25 \times 10^{-8} \mathrm{M}$ FMLP after 10-min pretreatment with G-CSF. A control experiment was carried out by adding the same amount of dimethylsulfoxide with cepharanthine. (a) Traces of $\mathrm{O}_{2}$ generation monitored by $\mathrm{Cyt} . \mathrm{c}$ in the presence or absence of various concentrations of cepharanthine. Broken line shows FMLP-induced $\mathrm{O}_{2}$ generation in the absence of G-CSF. (b) Dose-response curve for cepharanthine inhibition. 
a

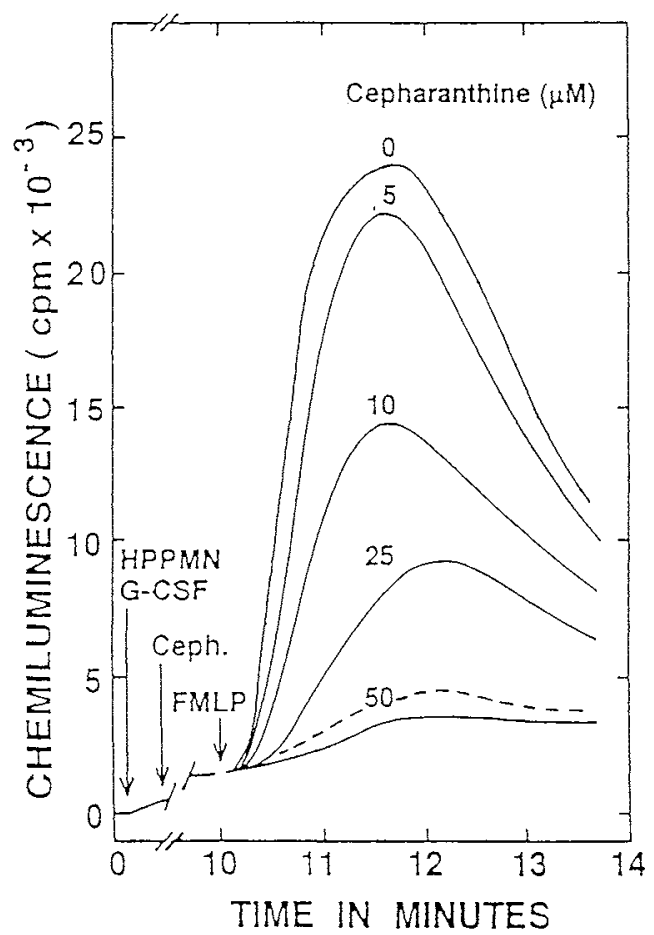

b

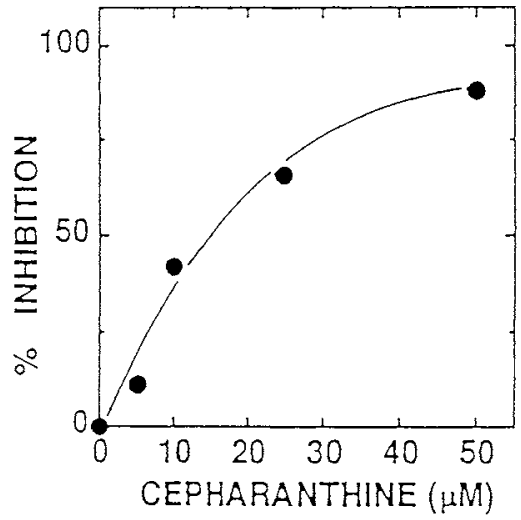

Fig. 2. Effect of cepharanthine on the FMLP-induced LCL response of G-CSF-treated HPPMN. LCL was monitored under the same conditions as those described in Fig. 1, except that $100 \mu \mathrm{M}$ luminol was added instead of Cyt. c. LCL was monitored with a calcium analyzer (Jasco CAF 100 , aequorin chemiluminescence mode). HPPMN $\left(1 \times 10^{5}\right.$ cells $\left./ \mathrm{ml}\right)$ were stimulated with $1.25 \times 10^{-8} \mathrm{M}$ FMLP after 10 min preincubation with $50 \mathrm{ng} / \mathrm{ml} \mathrm{G-CSF}$ at $37^{\circ} \mathrm{C}$. Broken line shows the LCL trace without G-CSF pretreatment. (a) FMLP-induced LCL responses after 10 min preincubation with G-CSF and the presence or absence of various concentrations of cepharanthine, (b) Dose-response curve for cepharanthine inhibition.

HPPMN was examined. However, cepharanthine inhibited the PMA-induced generation of $\mathrm{O}_{2}$ independently of the incubation time (Fig. 5). Cepharanthine also inhibited the PMA-induced LCL response independently of the incubation time (data not shown).

Effect of cepharanthine on tyrosyl phosphorylation of G-CSF-primed neutrophil proteins. Previous studies revealed that phosphorylation of tyrosine residues of several neutrophil proteins, such as 55, 58, 65, $84,98,108$, and $115 \mathrm{kDa}$ proteins, was increased by TNF- $\alpha$ (17). Other cytokines, such as GM-CSF (16), GCSF (17), and PAF (15), also enhanced the phosphorylation of neutrophil proteins. The tyrosyl phosphorylation of $58,65,84,108$, and $115 \mathrm{kDa}$ proteins was inhibited by cepharanthine in a concentration-dependent manner. When preincubated with $30 \mu \mathrm{M}$ cepharanthine for about $10 \mathrm{~min}, \mathrm{G}-\mathrm{CSF}$-induced phosphorylation of these proteins was remarkably inhibited (Fig. 6). However, no inhibition of the tyrosyl phosphorylation was observed in cells preincubated for less than $30 \mathrm{sec}$ (Fig. 7); thus, the inhibition also depended on the time of incubation with cepharanthine.

Effect of cepharanthine on EGF receptor/kinase-de- pendent phosphorylation of annexin $I$. Annexin $I$ is a good substrate for EGF receptor/kinase, a tyrosine kinase $(28,31)$. In the presence of $\mathrm{Ca}^{2+}$, annexin $\mathrm{I}$ binds to membrane surfaces where phosphatidylserine is located (32). Interestingly, annexin I is phosphorylated only when it binds to the membrane surface. However, cepharanthine showed no appreciable effect on the phosphorylation of annexin I even at high concentrations more than $0.1 \mathrm{mM}$ (data not shown). These results indicate that cepharanthine may not inhibit the activity of EGF receptor/kinase.

\section{DISCUSSION}

Many factors are involved in the mechanism for priming of neutrophils. For example, PAF (7) and ionomycin (33) evoked a high intracellular calcium peak and induced more marked response of the respiratory burst of FMLP-stimulated HPPMN. The increase in $\left(\mathrm{Ca}^{2+}\right)_{\mathrm{i}}$ might enhance translocation of PKC to plasma membrane, a prerequisite to the triggering of priming (34). Furthermore, it has been found that priming modulated the affinity of effective receptors (35), diacylglycerol 


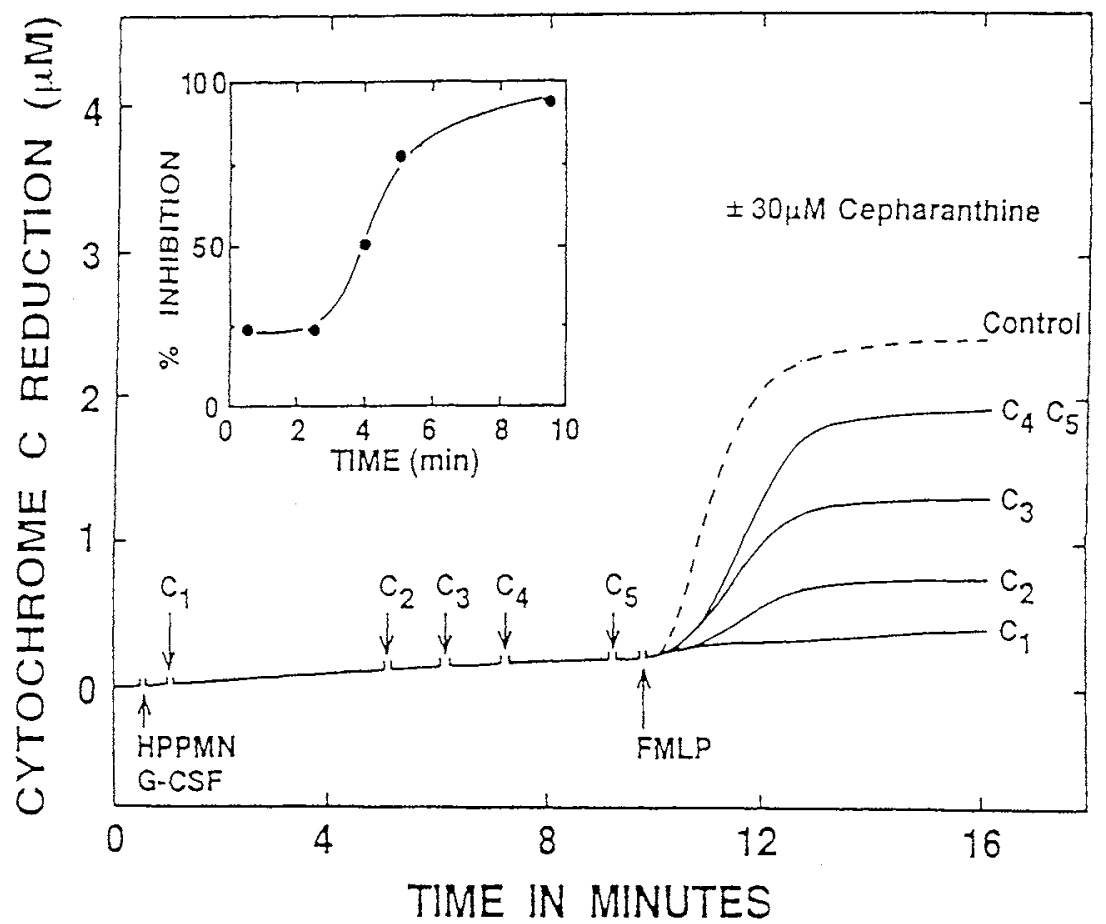

Fig. 3. Effect of preincubation time with cepharanthine on FMLP-induced $\mathrm{O}_{2}^{2}$ generation by G-CSF-treated HPPMN. Experimantal conditions were the same as those described in Fig. 1. Cepharanthine (30 $\mu \mathrm{M})$ was added at different times after the addition of G-CSF. Broken line shows $\mathrm{O}_{2}$ generation without the addition of cepharanthine. $\mathrm{C}_{1}-\mathrm{C}_{4}$ shows the time of cepharanthine addition before treatment with FMLP. Inset shows the time-dependent inhibition curve for cepharanthine.

levels (36), G-protein levels (37), levels of components of the NADPH-oxidase complex (38), and phospholipase D activity (39). The priming effects of G-CSF and TNF- $\alpha$ can be observed on the receptor-mediated $\mathrm{O} \dot{2}$ generation but not on the PKC-mediated process of nonprimed HHPMN $(12,13,29,30)$.

It has been thought that stimulus-coupled $\mathrm{O}_{2}$ generation depends on the phosphorylation of specific proteins, and that $\mathrm{PKC}$ activation plays important roles in the induction of respiratory bursts (10). However, neutrophil response was inhibited by PKC inhibitors only partially, suggesting the involvement of kinases other than PKC (11). In fact, tyrosyl phosphorylation of both cytosolic and membrane proteins occurred after treatment of cells with these priming agents (15-17). The increase in tyrosyl phosphorylation might reflect the increase in tyrosine kinase activity and/or the decrease in the activity of phosphotyrosine phosphatase. PMA and FMLP also increase tyrosyl phosphorylation in a time and concentration-dependent manner $(40,41)$. An increase in tyrosyl phosphorylation of neutrophil proteins was also observed after treatment of cells with guanine nucleotides (42) and G-proteins (43). These observations might indicate that the activation of G-protein is an initial step in the induction of neutrophil response to FMLP. Priming agents induced a time- and concentra- tion-dependent increase in the tyrosyl phosphorylation of neutrophil proteins, such as 115 and $84 \mathrm{kDa}$ proteins (15-17, 44, 45). The time and concentration dependence of tyrosyl phosphorylation is quite similar to that for the FMLP-dependent $\mathrm{O}_{2}$ generation of primed neutrophils. These results suggest that tyrosyl phosphorylation might underlie the mechanism for neutrophil priming.

The present study shows the effect of cepharanthine on HPPMN priming in relation to receptor-mediated $\mathrm{O}_{2}$ generation and protein tyrosyl-phosphorylation. Cepharanthine inhibited the $\mathrm{O} \dot{\overline{2}}$ generation of guinea pig peritoneal neutrophils (primed neutrophils) induced by various agents, such as FMLP, PMA, opsonized zymosan, and arachidonic acid $(19,20)$. Cepharanthine also inhibited the $\mathrm{O}$ generation of primed neutrophils by inhibiting PKC $(19,20)$. When nonprimed HPPMN were treated with both cepharanthine and G-CSF, FMLP-dependent $\mathrm{O}_{2}$ generation was inhibited, and the rate of inhibition depended on the time of preincubation with cepharanthine. In contrast, inhibition of PMA-stimulated $\mathrm{O}_{2}$ generation by cepharanthine occurred independently from the time of preincubation. These results indicate that the mechanisms of NADPH oxidase activation by FMLP and PMA might differ from each other, and that tyrosine kinase and protein ki- 
H. Kobuchi et al.

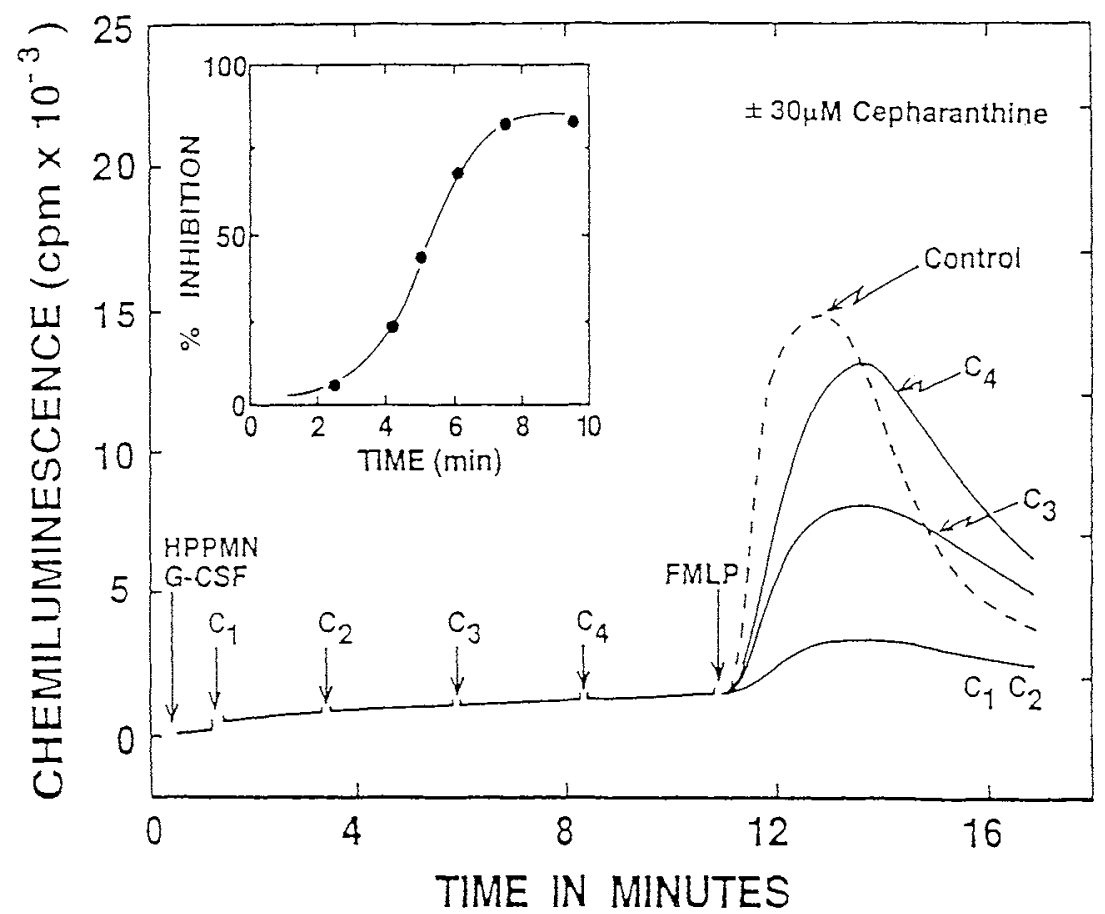

Fig. 4. Effect of preincubation time with cepharanthine on FMLP-induced LCL response of G-CSF-treated HPPMN. Experimantal conditions were the same as those described in Fig. 2. Cepharanthine was added at various times before the addition of FMLP. $C_{1}-C_{s}$ shows the time of cepharanthine addition. Inset shows the time-dependent inhibition curve for cepharanthine.

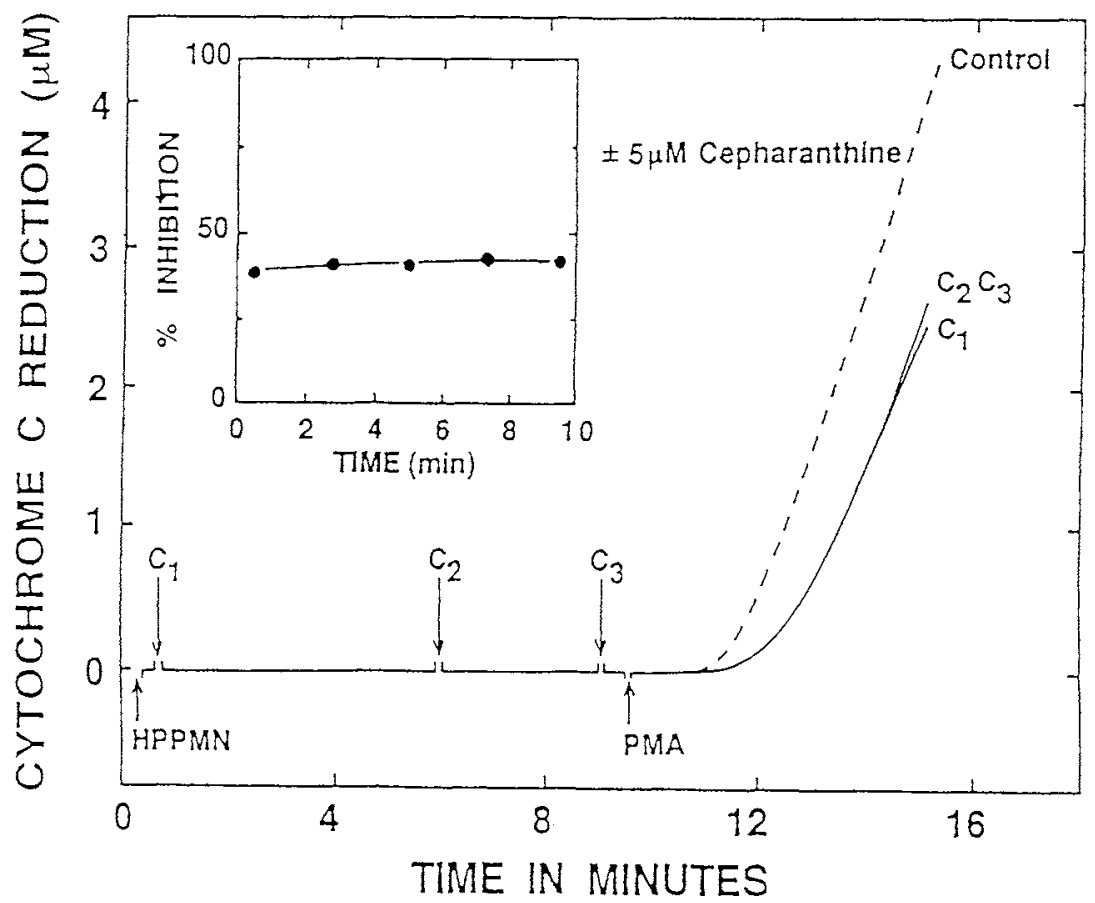

Fig. 5. Effect of preincubation time with cepharanthine on PMA-induced Ozeneration by HPPN. Experimantal conditions were the same as those described in Fig. 3 without adding G-CSF. $\mathrm{O}_{2}^{\frac{1}{2}}$ was generated by adding $1 \times 10^{-9} \mathrm{M}$ PMA and was inhibited by $40 \%$ with $5 \mu \mathrm{M}$ cepharanthine. 


\section{CBB Immuno blot}

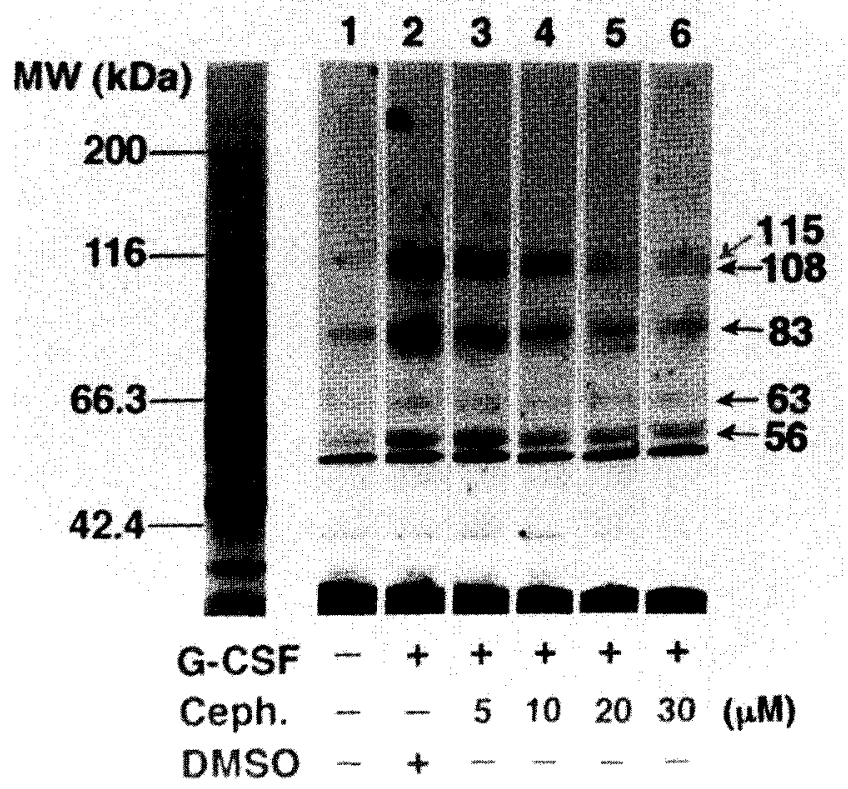

Fig. 6. Tyrosyl phosphorylation of neutrophil proteins after treatment with G-CSF and its inhibition by cepharanthine. HPPMN $(2 \times$ $10^{6}$ cells $/ \mathrm{ml}$ ) were incubated in KRP containing $1 \mathrm{mM} \mathrm{CaCl}_{2}, 10 \mathrm{mM}$ glucose, and $50 \mathrm{ng} / \mathrm{ml} \mathrm{G-CSF}$, in the presence or absence of various concentrations of cepharanthine, at $37^{\circ} \mathrm{C}$. The reaction was terminated by adding ice-cold $45 \%$ TCA containing $2 \mathrm{mM}$ PMSF and 1 $\mathrm{mM}$ sodium vanadate, and SDS-PAGE was carried out. After the transfer to an Immobilon-P filter, immunoblotting with monoclonal antiphosphotyrosine antibody was carried out and immunoreactives were detected with an ECL Western blotting detection system. Phosphorylation of $115,108,84$, and $55 \mathrm{kDa}$ proteins was inhibited by cepharanthine in a concentration-dependent manner.

nase $C$ might be involved in FMLP and PMA coupled pathways, respectively, in primed neutrophils. Furthermore, cepharanthine inhibited the G-CSF-induced tyrosyl phosphorylation of HPPMN proteins, such as 115 $\mathrm{kDa}$. The time-dependent inhibition of $\mathrm{O}_{2}$ generation by cepharanthine occurred in parallel with the inhibition of tyrosyl phosphorylation of the $115 \mathrm{kDa}$ protein. Thus, it seems likely that cepharanthine inhibited G-CSF-induced priming of neutrophils through the inhibition of tyrosyl phosphorylation. Since EGF receptor/kinase was not inhibited by cepharanthine and the priming was sensitive to pertussis toxin (12), it is suggested that cepharanthine possibly inhibits tyrosyl phosphorylation by interacting with G-proteins. Thus, the mechanisms for priming and its inhibition by cepharanthine should be studied further.

Acknowledgement. This work was supported by a grant-in-aid from the Ministry of Education, Science and Culture of Japan. A part of this work was also supported by a fund of the Japan Keirine Association. We express our gratitude to Dr. Kunihiro Akimaru, Dr.

\section{CBB Immuno blot}

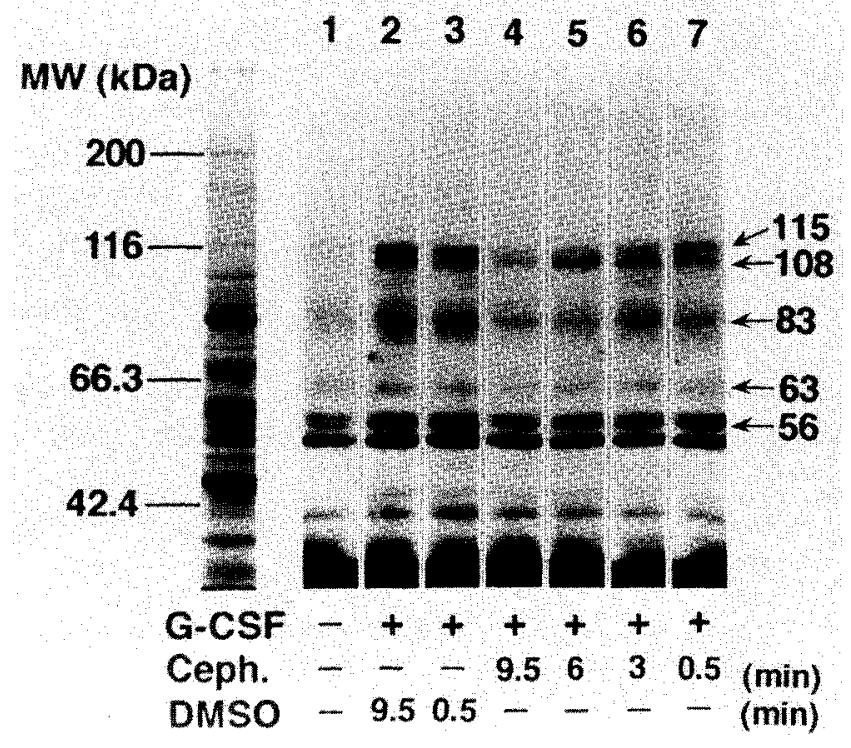

Fig. 7. Effect of preincubation time with cepharanthine $(30 \mu \mathrm{M})$ on tyrosyl phosphorylation in G-CSF-treated HHPMN. Experimantal conditions were the same as those described in Fig. 7. Time of treatment with cepharanthine was varied from $30 \mathrm{sec}$ to $9.5 \mathrm{~min}$. Tyrosyl phosphorylation of $115 \mathrm{kDa}$ and $84 \mathrm{kDa}$ proteins was inhibited when treatment with cepharanthine exceeded $5 \mathrm{~min}$.

Keisuke Edashige, and Dr. Eisuke F. Sato, for stimulating discusstion and suggestions on this work. We thank Mrs. Yoko Akimaru for her excellent technical help and Mrs. Taeko Okanishi for preparing the manuscript.

\section{REFERENCES}

1. Selvaraj, R.J. and Sbarra, A.J. (1966). Relationship of glycolytic and oxidative metabolism to particle entry and destruction in phagocytosine cells. Nature, 211: 1272-1276.

2. Weisbar, R.H., Kwan, L., Golde, D.W., and Gasson, J.C. (1987). Human GM-CSF primes neutrophils for enhanced oxidative metabolism in response to the major physiological chemoattractants. Blood, 69: 18-21.

3. Wirthmueller, U., DeWeck, A.L., and Dahinden, C.A. (1989). Platelet-activating factor production in human neutrophils by sequential stimulation with granulocyte-macrophage colony-stimulating factor and the chemotactic factors C5A or formyl-methionyl-leucyl-phenyl alanine. J. Immunol., 142: 32133218.

4. Shalaby, M.R., Aggarwal, B.B., Rinderknecht, E., Svedersky, L.P., Finkle, B.S., and Palladino, M.A. (1983). Activation of human polymorphonuclear neutrophil functions by interferon- $\gamma$ and tumor necrosis factors. $J$. Immunol., 135: 2069-2073.

5. Atkinson, Y.H., Marasco, W.A., Lopez, A.F., and Vadas, M.A. (1988). Recombinant human tumor necrosis factor- $\alpha$. Regulation of N-formyl-methionyl-leucyl-phenyl alanine receptor affinity and function of human neutrophils. J. Clin. Invest., 81: $759-765$. 
6. Guthrie, L.A., McPhail, L.C., Henderson, P.M., and Jonhston, R.B. (1984). Priming of neutrophils for enhanced release of oxygen metabolites by bacterial lipopolysaccharide. Evidence for increased activity of the superoxide-producing enzyme. J. Exp. Med., 160: 1656-1671.

7. Ingraham, L.M., Coates, T.D., Allen, J.M., Higgines, C.P., BAEHNER, R.L., and BoXer, L.A. (1982). Metabolic, membrane, and functional responses of human polymorphonuclear leukocytes to platelet-activating factor. Blood, 59: 1259-1266.

8. McPhail, L.C., Clayton, C.C., and Synderman, R. (1984). The NADPH oxidase of human polymorphonuclear leukocytes. Evidence for regulation by multiple signals. J. Biol. Chem., 259: 5768-5775.

9. Rossi, F. (1986). The $\mathrm{O}_{\overline{2}}$-forming NADPH oxidase of the phagocytes: nature, mechanisms of activation and functions. Biochim. Biophys. Acta, 853: 65-89.

10. NishizukA, Y. (1984). The role of protein kinase C in cell surface signal transduction and tumor promotion. Nature, 308: 693-698.

11. Sha'Afi, R.I., Molski, T.F., Gomez-Cambronero, J., and Huang, C.K. (1988). Dissociation of the 47-kilodalton protein phosphorylation from degranulation and superoxide production in neutrophils. J. Leukocyte Biol., 43: 18-27.

12. Utsumi, T., Klostergaard, J., Akimaru, K., Sato, E.F., Yoshioka, T., and UtsUmi, K. (1992). Effect of tumor necrosis factor- $\alpha$ on the stimulus-coupled responses of neutrophils and their modulation by various inhibitors. Physiol. Chem. \& Phys. and Med. NMR, 24: 77-88.

13. Utsumi, T., Klostergaard, J., Akimaru, K., Edashige, K., SATO, E.F., and UTSumi, K. (1992). Modulation of TNF- $\alpha-$ priming and stimulation dependent superoxide generation in human neutrophils by protein kinase inhibitors. Arch. Biochem. Biophys., 294: 271-278.

14. Tanimura, M., Kobuchi, H., Utsumi, T., Yoshioka, T., Kataoka, S., Fujita, Y., and Utsumi, K. (1992). Neutrophil priming by granulocyte colony stimulating factor and its modulation by protein kinase inhibitors. Biochem. Pharmacol., 44: 1045-1052.

15. Gomez-Cambronero, J., Wang, E., Johnson, G., Huang, C., and SHA'AFI, R.I. (1991). Platelet-activating factor induces tyrosine phosphorylation in human neutrophils. J. Biol. Chem., 266: 6240-6245.

16. McColl, S.R., DiPersio, J.F., Caon, A.C., Ho, P., and NACCACHE, P.H. (1991). Involvement of tyrosine kinase in the activation of human peripheral blood neutrophils by granulocyte-macrophage colony-stimulating factor. Blood, $\mathbf{7 8}$ : 1847-1852.

17. Akimaru, K., Utsumi, T., Sato, E.F., Klostergaard, J., INOUE, M., and UTSUMI, K. (1992). Role of tyrosyl phosphorylation in neutrophil priming by tumor necrosis factor-a and granulocyte colony stimulating factor. Arch. Biochem. Biophys., 298: 703-709.

18. Miyamoto, H. (1978). Management of nasal allergy-treatment with biscoclaurine alkaloid. Jibirinsho (in Japanese), 71: 185189.

19. Matsuno, T., Orita, K., Sato, E.F., Nobori, K., Inoue, B., and UTSUM, K. (1987). Inhibition of metabolic response of polymorphonuclear leukocyte by biscoclaurine alkaloids. Biochem. Pharmacol., 36: 1613-1616.

20. Matsuno, T., Orita, K., Edashige, K., Kobuchi, H., Sato, E.F., Inoue, B., Inoue, M., and Utsumi, K. (1990). Inhibition of active oxygen generation in guinea-pig neutrophils by biscoclaurine alkaloids. Biochem. Pharmacol., 39: 1255-1259.
21. Edashige, K., Utsumi, T., and Utsumi, K. (1992). Inhibition of 12-O-tetradecanoyl phorbol-13-acetate promoted tumorigenesis by cepharanthine, a biscoclaurine alkaloid, in relation to the inhibitory effect on protein kinase C. Biochem. Pharmacol., 41: 71-78.

22. Edashige, K., Utsumi, T., Sato, E.F., Ide, A., Kasai, M., and UTsUm, K. (1992). Requirement of protein association with membranes for phosphorylation by protein kinase C. Arch. Biochem. Biophys., 296: 296-301.

23. Sato, E.F., Tanaka, Y., Edashige, K., Kobuchi, H., Morishita, S., Sugino, Y.M., Inoue, M., and Utsumi, K. (1989). Expression of the cDNA encoding lipocortin-like 39 $\mathrm{kDa}$ protein of guinea pig neutrophils in yeast. FEBS Lett., 255: 231-236.

24. Weiss, S.J., Klein, R., SlivkA, A., and Wei, M. (1992). Chlorination of taurine by human neutrophils, evidence for hypochlorous acid generation. J. Clin. Invest., 70: 598-607.

25. Takahashi, R., Edashige, K., Sato, E.F., Inoue, M., Matsuno, T., and Utsumi, K. (1991). Luminol chemiluminescence and active oxygen generation by activated neutrophils. Arch. Biochem. Biophys., 285: 325-330.

26. Gelder, B.F. and SlAter, E.C. (1962). The extinction coefficient of cytochrome c. Biochim. Biophys., Acta, 58: 593-595.

27. Allen, R.C. (1986). Phagocytic leukocyte oxygenation activities and chemiluminescence. A kinetic approach to analysis. Methods in Enzymol., 133: 449-493.

28. DE, B.K., Misono, K.S., LuKas, T.J., Mroczkowski, B., and COHEN, S. (1986). A calcium-dependent 35-kilodalton substrate for epidermal growth factor receptor/kinase isolated from normal tissue. J. Biol. Chem., 261: 13784-13792.

29. Yuo, A., Kitagawa, S., Ohsaka, A., Ohta, M., Miyazono, K., OKabe, T., Urabe, A., Saito, M., and TakakU, F. (1989). Recombinant human granuclocyte colony-stimulating factor as an activator of human granulocytes: Potentiation of responses triggered by receptor-mediated agonists and stimulation of C3bi receptor expression and adherence. Blood, 74: 21442149.

30. Yuo, A., Kitagawa, S., Ohsaka, A., Saito, M., and Takaku, F. (1990). Stimulation and priming of human neutrophils by granulocyte colony-stimulating factor and granulocyte-macrophage colony-stimulating factor: Qualitative and quantitative differences. Biochim. Biophys. Res. Commun., 171: 491-497.

31. Pepinsky, R.B. and Sinclari, L.K. (1986). Epidermal growth factor-dependent phosphorylation of lipocortin. Nature, 321: 81-84.

32. Utsumi, K., Sato, E.F., Mryahara, M., and Takahashi, R. (1986). Calcium-dependent association of $33 \mathrm{kDa}$ protein in polymorphonuclear leukocytes with phospholipid liposomes containing phosphatidylserine or cardiolipin. FEBS Lett., 201: $277-281$.

33. Koenderman, L., YazdanbaKhsh, M., Roos, D., and VERHOEVEN, A.J. (1989). Dual mechanisms in priming of the chemoattractant-induced respiratory burst in human granulocytes. A $\mathrm{Ca}^{2+}$-dependent and a $\mathrm{Ca}^{2+}$-independent route. $J$. Immunol., 142: 623-628.

34. AIDA, Y. and PABST, M.J. (1990). Priming of neutrophils by lipopolysaccharide for enhanced release of superoxide requirement for plasma but not for tumor necrosis factor- $\alpha$. J. Immunol., 145: 3017-3025.

35. Vosbeck, K., Toblas, P., Muller, H., Allen, R.A., Arfors, K.E., Ulevitch, R.J., and SkLAR, L.A. (1990). Priming of polymorphonuclear granulocytes by lipopolysaccharides and its complexes with lipopolysaccharide binding protein and high 
density lipoprotein. J. Leukocyte Biol., 47: 97-104.

36. Reibman, J., Korchak, H.M., Vosshall, L.B., Haines, K.A., Rich, A.M., and WeISSMANN, G. (1988). Changes in diacylglycerol labeling, cell shape, and protein phosphorylation distinguish "triggering" from "activation" of human neutrophils. $J$. Biol. Chem., 263: 6322-6328.

37. McColl, S.R., Beauseigle, D., Gilbert, C., and Naccache, P.H. (1990). Priming of the human neutrophil respiratory burst by granulocyte-macrophage colony-stimulating factor and tumor necrosis factor- $\alpha$ involves regulation at a post-cell surface receptor level. J. Immunol., 145: 3047-3053.

38. Della Bianca, V., Grzeskowiak, M., Dusi, S., and Rossi, F. (1988). Fluoride can activate the respiratory burst independently of $\mathrm{Ca}^{2+}$, stimulation of phosphoinositide turnover and protein kinase $\mathrm{C}$ translocation in primed human neutrophils. Biochem. Biophys. Res. Commun., 150: 955-964.

39. Bauldry, S.A., Bass, D.A., Cousar, S.L., and McCall, C.E. (1991). Tumor necrosis factor $\alpha$ priming of phospholipase D in human neutrophils. J. Biol. Chem., 266: 4173-4179.

40. Berkow, R.L. and Dodson, R.W. (1990). Tyrosine-specific protein phosphorylation during activation of human neutrophils. Blood, 75: 2445-52.
41. Huang, C.K., Bonak, V., Laramee, G.R., and Casnellie, E. (1990). Protein tyrosine phosphorylation in rabbit peritoneal neutrophils. Biochem. J., 269: 431-436.

42. Nasmith, P.E., Mills, G.B., and Grinstein, S. (1989). Guanine nucleotides induce tyrosine phosphorylation and activation of the respiratory burst in neutrophils. Biochem. J., 257: 893897.

43. Grinstein, S. and Furuya, W. (1991). Tyrosine phosphorylation and oxygen consumption induced by $\mathrm{G}$ proteins in neutrophils. Am. J. Physiol., 260: C1019-C1027.

44. Gomez-Cambronero, J., Huang, C., Bonak, V.A., Wang, E., Casnellie, J.E., Shiraishi, T., and Sha'Afi, R.I. (1989). Tyrosine phosphorylation in human neutrophil. Biochem. Biophys. Res. Commun., 162: 1478-1485.

45. Gomez-Cambronero, J., Yamazaki, M., Metwally, F., Molski, T.F.P., BonaK, V.A., HUANG, C., BeCKer, E.L., and SHA'AFI, R.I. (1989). Granulcocyte-macrophage colony-stimulating factor and human neutrophils: Role of guanine nucleotide regulatory proteins. Proc. Nat. Acad. Sci. USA, 86: 35693573 .

(Received for publication, October 6, 1992

and in revised form, November 2, 1992) 